\title{
Activation Effects of a Platinum Electrode by Laser Pulse Irradiation on the Electro-Oxidation of Glucose in Alkaline Solution
}

\author{
Masato ChIKasou, Takakuni Hirabayashi, Toshio NaKamura, and Teruo HinOuE ${ }^{\dagger}$ \\ Department of Chemistry, Faculty of Science, Shinshu University, Asahi, Matsumoto 390-8621, Japan
}

\begin{abstract}
In order to demonstrate the activation effects of a Pt electrode by laser pulse irradiation, the electro-oxidation of glucose was tested at an activated Pt electrode by cyclic voltammetry. A fixed potential was applied to the electrode, and then the electrode was irradiated with laser pulses from a Nd:YAG laser at $20 \mathrm{~Hz}$ for $20 \mathrm{~s}$. Activation by the laser pulse irradiation gave two remarkable effects on cyclic voltammograms from the electro-oxidation of glucose in a $0.1 \mathrm{~mol} \mathrm{dm}^{-3}$ $\mathrm{NaOH}$ solution, i.e., surface modulation and cleaning effects. Significant differences were found in the cyclic voltammograms at the activated and at the simply polished electrodes. Such differences in the oxidation waves are attributed to a crystallographic change of the electrode surface induced by a laser ablation, accompanied by laser pulse irradiation. Due to the cleaning effect, the activated Pt electrode gave a sharp oxidation wave at $-0.3 \mathrm{~V}$ even in real samples containing various organic compounds that could foul the electrode, though the activated Pt electrode lacked selectivity to the electro-oxidation of glucose.
\end{abstract}

(Received March 16, 2004; Accepted June 28, 2004)

\section{Introduction}

The activation of solid electrodes has been an important subject in electroanalytical chemistry. The electrodes are frequently fouled with reactants and electrolyzed products, and hence cannot endure long-term use as an electrochemical detector. In particular, when a sample solution contains organic compounds, such as carbohydrates and alcohols, electrode fouling is a very serious problem. Hence, many treatments have been developed for activating electrodes, i.e., mechanical polishing, ${ }^{1,2}$ chemical or electrochemical treatment, ${ }^{3-6}$ heating treatment, ${ }^{7,8}$ radiofrequency plasmas treatment ${ }^{9,10}$ and laser pulse irradiation. ${ }^{11,12}$ Among such treatments, laser pulse irradiation is one of the convenient methods, since the electrode can be irradiated in the sample solution with laser pulses passing through an optical window attached to the electrolytic cell. An ablation action caused by laser pulse irradiation can not only clean the electrode surface, but also has the possibility to modify the surface structure, leading to a more active electrode surface for the electrode reaction. Recently, we also tried to activate $\mathrm{Pt}$ and $\mathrm{Au}$ electrodes by laser pulse irradiation, and proved that the electrooxidation of ascorbic acid is improved at activated electrodes. ${ }^{13,14}$ Further, because the ablation action can not only clean the electrode surface, but also renew the diffusion layer, we developed laser ablation voltammetry (LAV), in which a voltammogram is recorded by shooting a single laser pulse repeatedly at a fixed time intreval. ${ }^{13,15}$ LAV gives steady-state voltammograms similar to a polarogram, and the voltammograms are reproducible even for sample solutions

\footnotetext{
† To whom correspondence should be addressed.

E-mail: thinoue@gipac.shinshu-u.ac.jp
}

containing organic compounds that can foul the electrode surface. In our preliminary work, we simply applied LAV to the determination of glucose with a Pt electrode, since glucose is not only a representative of electrode-fouling compounds, but also one that the determination of which is of fundamental importance for studies on its metabolism and for the diagnosis of diseases, such as diabetes. As a result, reproducible voltammograms were obtained from the electro-oxidation of glucose, and a linear calibration line down to $c a .0 .01 \mathrm{mmol}$ $\mathrm{dm}^{-3}$ was achieved. However, LAV is unsuitable for examining the activation effects of the $\mathrm{Pt}$ electrode by laser pulse irradiation on the electro-oxidation of glucose. Since a single laser pulse is shot repeatedly at a fixed time interval in LAV, an activation effect other than the cleaning effect, that is, a surface modification effect of the laser pulse irradiation, is hardly observed. Thus, we irradiated the Pt electrode thoroughly with laser pulses, and examined the activation effects by cyclic voltammetry with the Pt electrode irradiated thoroughly. In this paper, we discuss significant differences between voltammograms obtained at the simply polished and the activated Pt electrodes, related to the electro-oxidation process of glucose. In addition, we actually demonstrate the cleaning and surface-modification effects of laser pulse irradiation through the voltammetric determination of glucose in real samples that contain various electrode-fouling compounds.

\section{Experimental}

\section{Experimental setup and measurement}

The experimental setup used was similar to that in previous work (Fig. 1). ${ }^{14}$ A Q-switched Nd:YAG laser (Quantel, Brilliant $\omega$ ) was used for irradiating the Pt electrode. The 


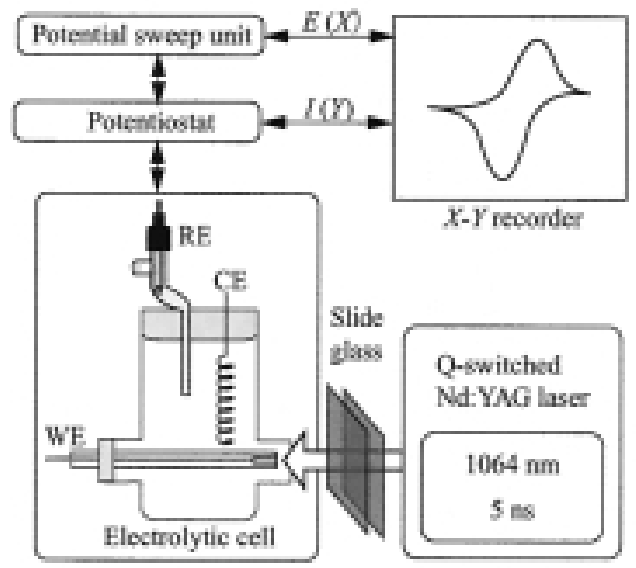

Fig. 1 Schematic diagram of the experimental setup.

energy was nominally $350 \mathrm{~mJ} /$ pulse at $1064 \mathrm{~nm}$ and the pulse width was $5 \mathrm{~ns}$. The pulse energy was measured with a laser power meter (OPHIR, 30A-P-SH, A/N2) in the atmosphere and adjusted to a proper value, usually $c a .80 \mathrm{~mJ} /$ pulse, by placing several slide glass plates between the electrolytic cell and the laser. A diameter of the laser spot was ca. $6 \mathrm{~mm}$ on the electrode surface and the spot was carefully positioned at the center of the Pt electrode with a fine adjustable X-Y stage. Voltammetric measurements were carried out with a potentiostat (Huso, HECS 972) and a potential sweep unit (Huso, HECS 980). The voltammograms were recorded on an $\mathrm{X}-\mathrm{Y}$ recorder (Yokogawa Electric Work, Ltd., 3086). The working electrode was prepared by tightly inserting a Pt wire of $1.0 \mathrm{~mm}$ in diameter (Nilaco, 99.98\%) into a Teflon rod of 10 $\mathrm{mm}$ in diameter and by roughly polishing the end. After the electrode surface was polished with 0.3 and $0.05 \mu \mathrm{m}$-aluminapowder slurry and rinsed in deionized water ultrasonically, it was horizontally inserted into the electrolytic cell (Fig. 1). Before each measurement, the Pt electrode was irradiated with laser pulses at $20 \mathrm{~Hz}$ for $20 \mathrm{~s}$. All potentials are referred to a saturated calomel electrode (SCE); a platinum spiral wire was used as a counter electrode. The sample solutions were purged with nitrogen gas $(99.9 \%)$ for at least $20 \mathrm{~min}$ before each voltammetric measurement. The measurements were performed at room temperature $\left(25 \pm 1^{\circ} \mathrm{C}\right)$.

\section{Reagents}

D-Glucose, D-fructose, D-galactose, and L-ascorbic acid were purchased from Nacalai Tesque and used without further purification. The other reagents used were of reagent grade; deionized water was used for preparing all solutions.

\section{Enzyme electrode for the amperometric determination of glucose}

An enzyme electrode for the determination of glucose was prepared according to a procedure proposed by Okuda et al. ${ }^{16-18}$ Carbon paste (BAS, CPO carbon paste Oil Base), 1,1'dimethylferrocene (Tokyo Kasei) and glucose oxidase (Touyou Bousei) were mixed with a mass ratio of 8:1:1. The mixture was inserted into a Pyrex glass tube of $1 \mathrm{~mm}$ in diameter and dried for at least $6 \mathrm{~h}$ in a refrigerator at $6^{\circ} \mathrm{C}$. Before each amperometric measurement, the enzyme electrode was carefully polished on a Teflon sheet and the amperograms were recorded on a Y-t recorder (Toa Denpa Kogyo, FBR-251A). When not in use, the electrode was stored in a refrigerator.
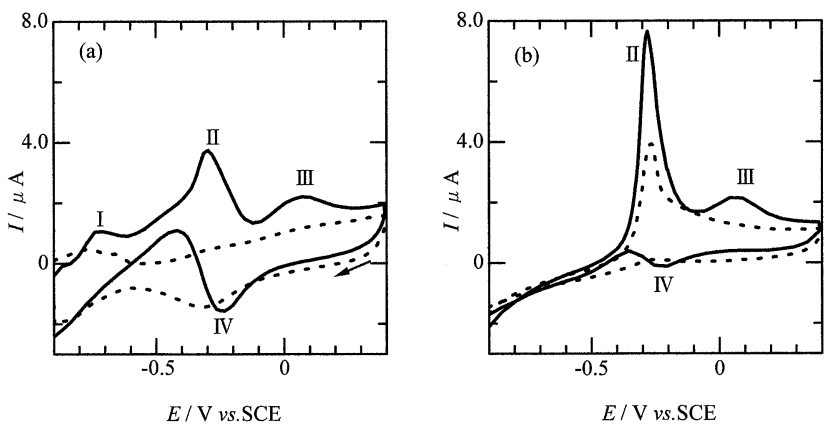

Fig. 2 Cyclic voltammograms from a blank solution $\left(0.1 \mathrm{~mol} \mathrm{dm}^{-3}\right.$ $\mathrm{NaOH}$, the broken line $)$ and from a sample solution $\left(0.1 \mathrm{~mol} \mathrm{dm}^{-3}\right.$ $\mathrm{NaOH}+10 \mathrm{mmol} \mathrm{dm}^{-3}$ glucose, the solid line) at a polished $\mathrm{Pt}$ electrode (a) and at an activated Pt electrode (b). The potential was swept at a rate of $50 \mathrm{mV} \mathrm{s}^{-1}$ between -0.9 and $0.4 \mathrm{~V}$. The $\mathrm{Pt}$ electrode was activated at $-0.9 \mathrm{~V}$ in the solutions by laser pulse irradiation at $20 \mathrm{~Hz}$ for $20 \mathrm{~s}$ at an intensity of $c a .80 \mathrm{~mJ} /$ pulse.

\section{Spectrophotometric determination of glucose}

For the determinations of glucose, spectrophotometry was also carried out by the hexokinase (HX) method with a conventional spectrophotometer. ${ }^{19,20}$

\section{Microscopic observation of Pt plate surfaces}

For microscopic observations of the $\mathrm{Pt}$ plate surfaces irradiated with the laser pulses at various pulse intensities, a scanning electron microscope (KEYENCE, VE-7800) was employed at an accelerating voltage of $20 \mathrm{kV}$.

\section{Results and Discussion}

Electro-oxidation of glucose: differences between cyclic voltammograms obtained at the Pt electrodes simply polished and activated by laser pulse irradiation

Figure 2(a) shows cyclic voltammograms (CVs) from a blank solution $\left(0.1 \mathrm{~mol} \mathrm{dm}^{-3} \mathrm{NaOH}\right)$ and from a sample solution $(0.1$

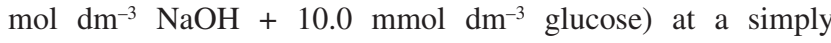
polished Pt electrode (polished electrode). The CV of the polished electrode showed three oxidation waves (I, II, and III) and one reduction wave (IV). The oxidation wave I is reported as being due to the oxidation of hydrogen atoms $\left(\mathrm{H}_{\mathrm{ads}}\right)$ formed from the dehydrogenation of glucose adsorbed on the electrode, $(\mathrm{OR}-\mathrm{CH}-\mathrm{OH})_{\mathrm{ads}}$. The electrode reaction is expressed as follows: ${ }^{21-23}$

$$
\begin{aligned}
& \mathrm{OR}-\mathrm{CH}-\mathrm{OH} \rightleftharpoons(\mathrm{OR}-\mathrm{CH}-\mathrm{OH})_{\mathrm{ads}}, \\
& (\mathrm{OR}-\mathrm{CH}-\mathrm{OH})_{\mathrm{ads}} \longrightarrow(\mathrm{OR}-\mathrm{C}-\mathrm{OH})_{\mathrm{ads}}+\mathrm{H}_{\mathrm{ads}},
\end{aligned}
$$

$$
\mathrm{H}_{\mathrm{ads}} \rightleftharpoons \mathrm{H}^{+}+\mathrm{e}^{-} \text {. }
$$

Further, it has been reported that catalytic decomposition following Eq. (2) produces hydrogen molecules and gluconolactone. ${ }^{22}$ An in situ infrared spectroscopic study has suggested that the catalytic decomposition leaves carbon monoxide chemisorbed on the electrode, $\mathrm{CO}_{\text {ads. }}{ }^{21}$ Oxidation peak II appears in the potential region where a slight oxidation wave can be seen in the CV for the blank solution, indicating that the electrode surface is partially oxidized. The resultant oxidized species on the electrode, $\mathrm{Pt}(\mathrm{OH})_{\mathrm{ads}}$, oxidizes $(\mathrm{OR}-\mathrm{C}-\mathrm{OH})_{\text {ads }}$ and/or $\mathrm{CO}_{\text {ads }}$ to produce gluconolactone, $\mathrm{OR}-\mathrm{CO}$ 
and/or carbon dioxide. ${ }^{22,24}$ That is,

$$
\begin{aligned}
& \mathrm{Pt}+\mathrm{OH}^{-} \longrightarrow \mathrm{Pt}(\mathrm{OH})_{\text {ads }}+\mathrm{e}^{-}, \\
& (\mathrm{OR}-\mathrm{C}-\mathrm{OH})_{\mathrm{ads}}+\mathrm{Pt}(\mathrm{OH})_{\mathrm{ads}} \longrightarrow \mathrm{Pt}+\mathrm{OR}-\mathrm{CO}+\mathrm{H}_{2} \mathrm{O},
\end{aligned}
$$

$$
\mathrm{OR}-\mathrm{CO}+\mathrm{H}_{2} \mathrm{O} \rightleftharpoons \mathrm{HOR}-\mathrm{COOH} \text {, }
$$

$$
\mathrm{CO}_{\mathrm{ads}}+\mathrm{Pt}(\mathrm{OH})_{\mathrm{ads}} \longrightarrow \mathrm{Pt}+\mathrm{CO}_{2}+\mathrm{H}^{+}+\mathrm{e}^{-} .
$$

Gluconolactone may hydrolyze to gluconic acid, HOR-COOH, following Eq. (5). ${ }^{25}$ These electrode and surface reactions are assumed to be responsible for oxidation peak II. As described later, the peak current of oxidation peak II, measured at the activated Pt electrode by laser pulse irradiation, was used to make a calibration line of glucose. Oxidation wave III around $0.1 \mathrm{~V}$ is attributed to the oxidation of glucose that diffuses from the bulk solution to the electrode, since the peak current is proportional to the square root of the sweep rate. However, the oxidation mechanism is quite complicated. It is proposed that platinum oxide, $\mathrm{PtO}$, which is formed on the electrode in this potential region, can oxidize glucose to gluconolactone and gluconic acid through a fast process. ${ }^{24}$ That is,

$$
\mathrm{OR}-\mathrm{CH}-\mathrm{OH}+\mathrm{PtO} \longrightarrow \mathrm{Pt}+\mathrm{OR}-\mathrm{CO}+\mathrm{H}_{2} \mathrm{O} \text {, }
$$

$$
\mathrm{OR}-\mathrm{CO}+\mathrm{H}_{2} \mathrm{O} \rightleftharpoons \mathrm{HOR}-\mathrm{COOH} \text {. }
$$

The reduction wave IV has been attributed to a reduction of the platinum oxide formed during a positive-going sweep. A similar wave can be seen on the $\mathrm{CV}$ from the blank solution.

Figure 2(b) shows the CVs at the Pt electrode activated by laser pulse irradiation (activated electrode). The CVs were obtained immediately after activating the Pt electrode under an applied potential of $-0.9 \mathrm{~V}$ by irradiating the polished electrode with laser pulses at $20 \mathrm{~Hz}$ for $20 \mathrm{~s}$. Significant differences were found between the $\mathrm{CVs}$ at the activated and polished electrodes. The first was the disappearance of oxidation wave I at the activated electrode. The disappearance of oxidation wave I can be due to the removal of glucose adsorbed on the electrode, $(\mathrm{OR}-\mathrm{CH}-\mathrm{OH})_{\mathrm{ads}}$, by the ablation action accompanied by laser pulse irradiation, and/or to a structural modification of the electrode surface induced by the ablation action. It is, however, reasonable that glucose would be adsorbed within a few seconds from the laser pulse irradiation before the potential sweep measurement, even though the adsorption of glucose with hydrogenation, expressed by Eqs. (1) and (2), is assumed to be a rate-determining step. ${ }^{22,23,26}$ Further, another oxidation wave, which has been reported to have the same character as the oxidation wave $I, 22,23$ could not be observed in the negativegoing sweep in the potential region where oxidation wave I appeared. We expected that the oxidation wave should be observed at the activated electrode, since sufficient time for the adsorption of glucose would have passed during the negativegoing sweep. Consequently, the disappearance of oxidation wave I is probably not due to the removal of adsorbed glucose, but to a structural modification of the electrode surface induced by the ablation action. The second difference is that oxidation peak II becomes considerably sharper at the activated electrode. This difference is also evident on the $\mathrm{CV}$ from the blank solution. Although an oxidation wave in the potential region from -0.4 to $-0.2 \mathrm{~V}$ could be seen in the $\mathrm{CV}$ at the polished electrode, a clear and sharp oxidation wave could be seen at $-0.3 \mathrm{~V}$ at the activated electrode. These facts suggest that oxidation peak II for the sample solution was closely related to
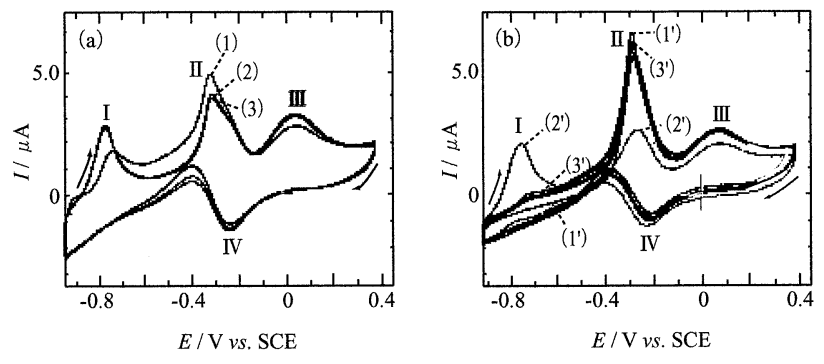

Fig. 3 Multi-cyclic voltammograms (MCVs) from the sample solution ( $0.1 \mathrm{~mol} \mathrm{dm}^{-3} \mathrm{NaOH}+10 \mathrm{mmol} \mathrm{dm}^{-3}$ glucose) at a polished Pt electrode (a) and at an activated Pt electrode (b). (1) The first cycle, (2) after continuous cycling for $30 \mathrm{~min}$, (3) after continuous cycling for $60 \mathrm{~min}$. (1') Immediately after the laser pulse irradiation, $\left(2^{\prime}\right)$ after continuous cycling for $30 \mathrm{~min}$ following measurements of CV (1'), ( $\left.3^{\prime}\right)$ immediately after the laser pulse irradiation following the measurement of $\mathrm{CV}\left(2^{\prime}\right)$. The other conditions are as in Fig. 2.

the oxidation wave observed at $-0.3 \mathrm{~V}$ in the $\mathrm{CV}$ of the blank solution. According to a study by Popović et al. on the electrooxidation of glucose at a single-crystal Pt electrode, ${ }^{22}$ only a CV at the electrode surface with a crystallographic index (111) shows a sharp oxidation wave at the potential corresponding to $-0.3 \mathrm{~V}$ vs. SCE in $0.1 \mathrm{~mol} \mathrm{dm}^{-3} \mathrm{NaOH}$. It is therefore assumed that the sharpness of the oxidation wave at $-0.3 \mathrm{~V}$ for the blank solution resulted from a structural modification of the polycrystaline electrode surface to the (111)-rich one by laser pulse irradiation. This assumption seems to be consistent with the cause of the disappearance of oxidation wave I. In addition, the similarity in shape between oxidation wave II for the sample solution and the oxidation wave at $-0.3 \mathrm{~V}$ for the blank solution supports a surface reaction between $(\mathrm{OR}-\mathrm{C}-\mathrm{OH})_{\text {ads }}$ and/or $\mathrm{CO}_{\mathrm{ads}}$ and $\mathrm{Pt}(\mathrm{OH})_{\text {ads }}$, expressed by Eqs. (4) - (6), since the oxidation wave for the blank solution is related to the formation of $\mathrm{Pt}(\mathrm{OH})_{\text {ads }}$.

Oxidation wave III at the activated electrode seems to be similar to that at the polished electrode in shape, and presents characteristics of diffusion control. Thus, one may conclude that the reaction mechanism for oxidation wave III at the activated electrode is identical to that at the polished electrode. In addition, the reduction wave IV at the activated electrode was observed in a similar way to that at the polished electrode, although with smaller currents. This wave was clearly due to the reduction of oxidized species formed on the surface of Pt.

Demonstration of the cleaning effect and a surface modification As mentioned in Introduction, we have already achieved a detection limit of $c a .0 .01 \mathrm{mmol} \mathrm{dm}{ }^{-3}$ by LAV in preliminary work. Since LAV gives steady-state voltammograms, and hence reproducible data, we can expect that LAV is superior to cyclic voltammetry in sensitivity for the determination of glucose. However, in order to clearly demonstrate the cleaning and surface-modification effects of laser pulse irradiation, we dared to try to determine glucose using cyclic voltammetry. Several factors affecting the determination of glucose and selectivity of the activated Pt electrode to the electro-oxidation of glucose were examined, as shown below.

Recovery of the cyclic voltammogram by laser pulse irradiation. Figure 3 shows multi-cyclic voltammograms (MCVs) from the oxidation of glucose at the polished Pt electrode (a) and at the activated Pt electrode (b). Curve (1) in the MCV (a) indicates a $\mathrm{CV}$ obtained in the first cyclic sweep after polishing the electrode, curve (2) after continuous cycling for $30 \mathrm{~min}$ and 


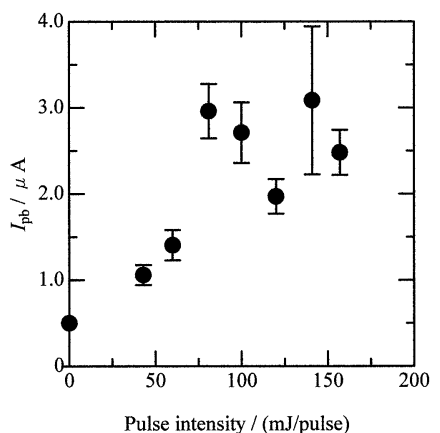

Fig. 4 Dependence of the peak current at $-0.3 \mathrm{~V}$ from the blank solution $\left(0.1 \mathrm{~mol} \mathrm{dm}^{-3} \mathrm{NaOH}\right)$ on the laser pulse intensity. The circles indicate the average peak currents and the bars standard deviations $(n=10)$. The irradiation time was $20 \mathrm{~s}$. The conditions for the CV measurements are as in Fig. 2.

curve (3) after 60 min cycling. The oxidation waves I and II gradually became larger and smaller during the first cycles, and then approached to a steady wave. This indicates that the electrode fouling with glucose and/or its decomposed species soon settled into a fixed condition. In contrast to the MCV at the polished electrode, a dramatic change was observed in the MCV at the activated electrode. Curve $\left(1^{\prime}\right)$ in the MCV (b) indicates a $\mathrm{CV}$ obtained in the first cycle immediately after irradiating the electrode with laser pulses and curve $\left(2^{\prime}\right)$ after continuous cycling for $30 \mathrm{~min}$. Curve $\left(3^{\prime}\right)$ indicates the CV obtained immediately following laser pulse irradiation after recording curve $\left(2^{\prime}\right)$. While oxidation wave I was not observed at the electrode immediately after laser pulse irradiation, continuous cycling for $30 \mathrm{~min}$ allowed oxidation wave I to appear, as can be seen in curve $\left(2^{\prime}\right)$. On the other hand, while oxidation wave II showed a sharp and high peak at the freshly activated electrode, after continuous cycling for $30 \mathrm{~min}$, it became a broad wave with a low peak similar to oxidation wave II at the polished electrode. These experimental facts observed for oxidation waves I and II indicate that electrode activation by laser pulse irradiation fades away soon because of strong electrode fouling by glucose and/or fragments adsorbed on the electrode surface. However, the new laser pulse irradiation could clean the electrode surface and allow the electrode to recover an active (111)-rich surface. As can be seen in curve $\left(3^{\prime}\right)$, oxidation wave I disappears again and oxidation wave II returns to the original sharp one. No differences were observed in oxidation waves III and IV between before and after laser pulse irradiation, as expected from the characteristics of oxidation waves III and IV. Thus, it is evident that electrode activation by laser pulse irradiation can give reproducible CVs from solutions containing glucose.

Dependence of the peak current on the laser pulse intensity. In order to examine a threshold of the laser pulse intensity for a surface modification of the Pt electrode, the peak current of the oxidation wave at $-0.3 \mathrm{~V}$ for the blank solution, $I_{\mathrm{pb}}$, was examined by changing the laser pulse intensity. Figure 4 shows the dependence of the peak current on the laser pulse intensity. Although the peak current increased with the intensity in the range to $80 \mathrm{~mJ} /$ pulse, the peak currents were relatively small and the oxidation waves were broad. In the range greater than $80 \mathrm{~mJ} /$ pulse, the peak currents attained an almost constant value and the oxidation waves were sharp. The threshold value of 80 $\mathrm{mJ} /$ pulse, corresponding to $280 \mathrm{MW} \mathrm{cm}{ }^{-2}$, fairly agrees with that in previous work, ${ }^{15}$ but which is much greater than that for activating a glassy carbon electrode. ${ }^{11}$ When the intensity

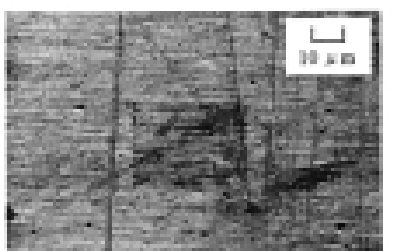

(a) Not irradiated

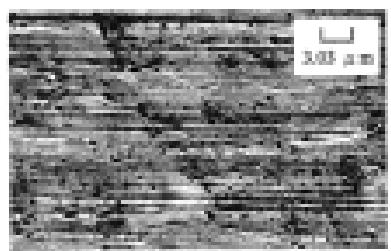

(c) $80 \mathrm{~mJ} /$ pulse

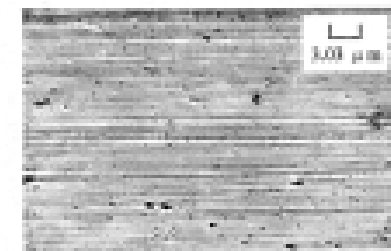

(b) $40 \mathrm{~mJ} /$ pulse

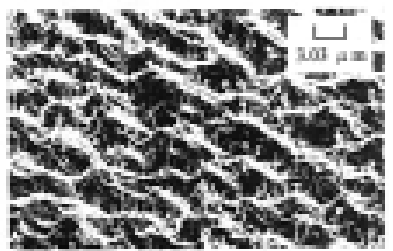

(d) $300 \mathrm{~mJ} /$ pulse
Fig. 5 SEM images of Pt surfaces irradiated with laser pulses at different laser pulse intensities in $0.1 \mathrm{~mol} \mathrm{dm}^{-3} \mathrm{NaOH}$. The irradiation time of the laser pulse was $20 \mathrm{~s}$ at $20 \mathrm{~Hz}$. The accelerating voltage was $20 \mathrm{kV}$.

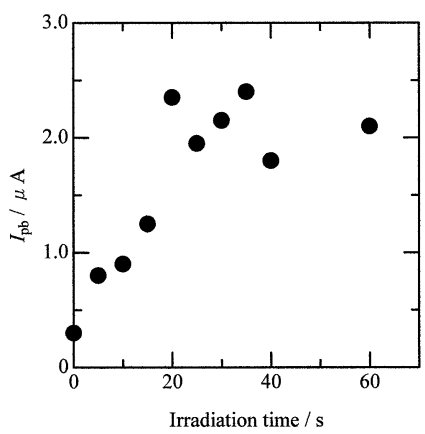

Fig. 6 Dependence of the peak current at $-0.3 \mathrm{~V}$ from the blank solution $\left(0.1 \mathrm{~mol} \mathrm{dm}^{-3} \mathrm{NaOH}\right)$ on the irradiation time. The laser pulse intensity was kept constant at $91 \mathrm{~mJ} /$ pulse. The conditions for the $\mathrm{CV}$ measurements are as in Fig. 2.

increased beyond $140 \mathrm{~mJ} /$ pulse, the current flow stopped for a while after irradiation on the voltammetric measurement, though the peak currents were as large as those in the range from 80 to $100 \mathrm{~mJ} /$ pulse. The ablation action at such strong intensities may instantaneously form a passive layer on the electrode surface. Based on the intensity dependence, the intensity of $c a .80 \mathrm{~mJ} /$ pulse was usually used for activation.

Figure 5 displays scanning electron microscopic (SEM) images of a Pt plate surface not irradiated with the laser pulses (a) and irradiated at 40 (b), 80 (c) and $300 \mathrm{~mJ} / \mathrm{pulse}$ (d) in 0.1 mol $\mathrm{dm}^{-3} \mathrm{NaOH}$. The vertical lines in image (a) are traces scripted during the polishing process. Images (a), (b) and (c) seem to be similar to each other in this observation. On the other hand, undulatory roughness can be seen in image (d), which allows us to conclude that laser pulse irradiation at such a high intensity as $300 \mathrm{~mJ} /$ pulse damages the Pt plate surface through the ablation action. Taking the fact into account that $I_{\mathrm{pb}}$ was almost constant at intensities greater than $80 \mathrm{~mJ} /$ pulse (Fig. 4), these images suggest that the sharp appearance of the oxidation peak at $-0.3 \mathrm{~V}$ for the blank solution was not caused by such a large structural change as the undulatory roughness, shown in the image (d), but by a fine structural change that could not be observed with the microscope used in this work.

Dependence of the peak current on the irradiation time. The peak current, $I_{\mathrm{pb}}$, was also examined by changing the irradiation 
(a) galactose

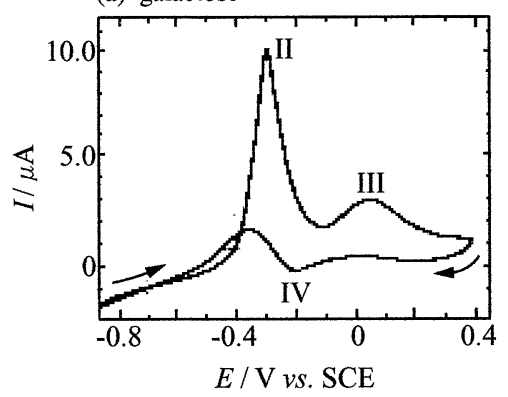

(b) fructose

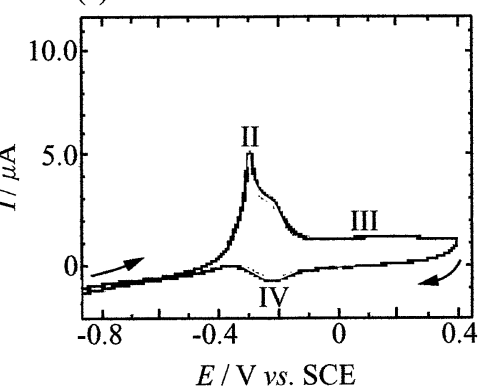

(c) glucose

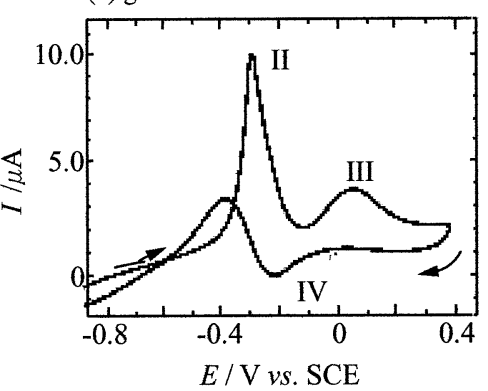

Fig. 7 Cyclic voltammograms of galactose (a), fructose (b) and glucose (c) in 0.1 mol $\mathrm{dm}^{-3} \mathrm{NaOH}$ at the Pt electrode activated by laser pulse irradiation. The other conditions are as in Fig. 2.

time from 5 to $30 \mathrm{~s}$ at $91 \mathrm{~mJ} /$ pulse. A CV was recorded immediately after irradiation of the Pt electrode at $20 \mathrm{~Hz}$ for each irradiation time in the blank solution. The peak currents at $-0.3 \mathrm{~V}$ were obtained from the CVs and plotted against the irradiation time, as shown in Fig. 6. For an irradiation time beyond $20 \mathrm{~s}$, the peak current became almost constant, meaning that it took at least $20 \mathrm{~s}$ to ablate the whole Pt electrode surface uniformly. Thus, an irradiation time of $20 \mathrm{~s}$ was used in all voltammetric experiments for the determination of glucose.

Relationship between the peak current and the concentration of glucose. The peak currents at $-0.3 \mathrm{~V}$ were measured for samples containing different concentrations of glucose. After subtracting the peak current due to the blank solution, the corrected peak currents were plotted against the concentration of glucose. The corrected peak currents were proportional to the concentration to $10 \mathrm{mM}$. However, the sensitivity obtained in each experiment, which is a slope of the corrected peak current $v s$. the concentration curve, was considerably dependent on the peak current for the blank solution $\left(I_{\mathrm{pb}}\right)$. This fact not only implies that glucose is oxidized by the surface oxidized species, $\mathrm{Pt}(\mathrm{OH})_{\text {ads }}$, as expressed by Eqs. (4) - (6), but also suggests that the present experimental procedure of laser pulse irradiation is still not sufficient to activate the Pt electrode in a fixed surface condition.

From the viewpoint of determining glucose, if laser pulse irradiation is used as the activation treatment of a Pt electrode, the voltammetric determination seems to be applicable to samples like blood and soft drinks that contain glucose from a few to several hundreds mmol $\mathrm{dm}^{-3}$. However, the selective determination of glucose in real samples, which contain other monosaccharides, is difficult, since the activated Pt electrode lacks selectivity to the electro-oxidation of glucose (The lack of the selectivity is the same in LAV). CVs of other monosaccharides showed oxidation waves similar to the oxidation wave II for glucose, as shown later.

Cyclic voltammograms of galactose, fructose and ascorbic acid. Figure 7 gives cyclic voltammograms of galactose (a), fructose (b) and glucose (c). All CVs showed oxidation waves II and III, though they did not show oxidation wave I. These facts are reasonable, since monosaccharides are identical in their chemical properties and the same electrode reaction is expected to occur. However, the $\mathrm{CV}$ of fructose showed little differences in shape from those of the others. These differences are probably attributed to the differences in their molecular structure. Glucose and galactose have an aldehyde group at C1 , and fructose presents a keto group at C-2. The aldehyde group contains a hydrogen atom readily pulled out during the electro-oxidation process, whereas the keto group has no hydrogen atom. The potential region in which the oxidation
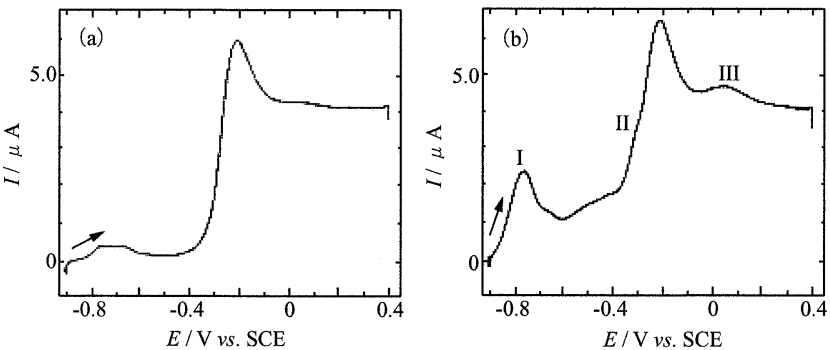

Fig. 8 Linear sweep voltammograms of $6 \mathrm{mmol} \mathrm{dm}^{-3}$ ascorbic acid (a) and $6 \mathrm{mmol} \mathrm{dm}^{-3}$ glucose $+6 \mathrm{mmol} \mathrm{dm}^{-3}$ ascorbic acid (b) in 0.1 mol $\mathrm{dm}^{-3} \mathrm{NaOH}$ at the Pt electrode activated by laser pulse irradiation. The other conditions are as in Fig. 2.

wave II appeared was almost the same as in the three CVs. It is therefore suggested that voltammetry, including LAV, at the activated Pt electrode is a good tool, but only for determining the total monosaccharides.

Ascorbic acid (AA) serves as a reductant in a similar way to glucose, and hence can interfere in the determination of glucose. Figure 8 shows linear sweep voltammograms (LSVs) for a 0.1 mol dm${ }^{-3} \mathrm{NaOH}$ solution containing $6 \mathrm{mmol} \mathrm{dm}^{-3} \mathrm{AA}$ (a) and containing $6 \mathrm{mmol} \mathrm{dm}^{-3} \mathrm{AA}$ and $6 \mathrm{mmol} \mathrm{dm} \mathrm{dm}^{-3}$ glucose (b) at the activated Pt electrode. While the oxidation wave of AA can be clearly seen at $-0.2 \mathrm{~V}$ in both LSVs, the oxidation wave II of glucose appears only as a shoulder preceding the oxidation wave of AA, which indicates that AA strongly interferes in the determination of glucose. Although oxidation wave III can be seen on the oxidation wave of AA, it is difficult to avoid the interference of $\mathrm{AA}$ at the present stage. If the activated $\mathrm{Pt}$ electrode was used as an amperometric detector of a chromatographic apparatus, the interference by AA and other monosaccharides could be avoided. Curiously, oxidation wave I could not be removed in the presence of AA. With respect to this, it is unclear at present whether the presence of AA contributed to the appearance of oxidation peak I.

Determination of glucose in soft drinks. The determination of glucose was carried out at the activated $\mathrm{Pt}$ electrode for carbonated and lactic acid drinks, both sold at the market without ascorbic acid. LSVs for these samples are shown in Fig. 9. Voltammograms (a) and (b) were obtained for the carbonated and the lactic acid drink, respectively. Curves, (1), (2) and (3) are voltammograms for the blank solution $(0.1 \mathrm{~mol}$ $\left.\mathrm{dm}^{-3} \mathrm{NaOH}\right)$, a sample solution $\left(50 \mathrm{~cm}^{3}\right.$ of $0.1 \mathrm{~mol} \mathrm{dm}{ }^{-3} \mathrm{NaOH}$ $+0.200 \mathrm{~cm}^{3}$ of carbonated drink or lactic acid drink) and a sample solution with $0.3 \mathrm{mmol}$ glucose added, respectively. As 
(a) Carbonated drink
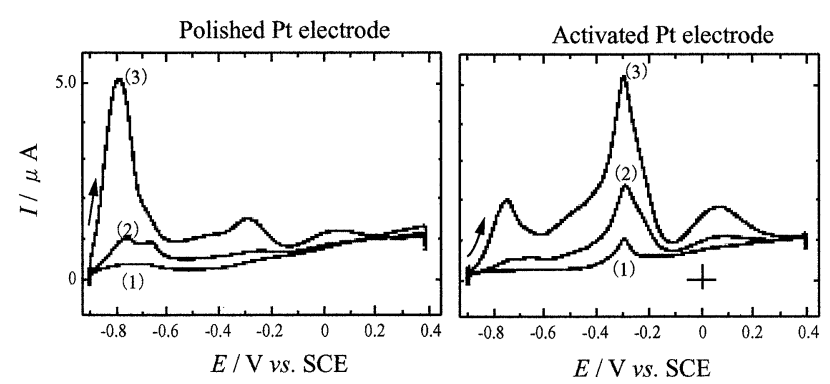

(b) Lactic acid drink

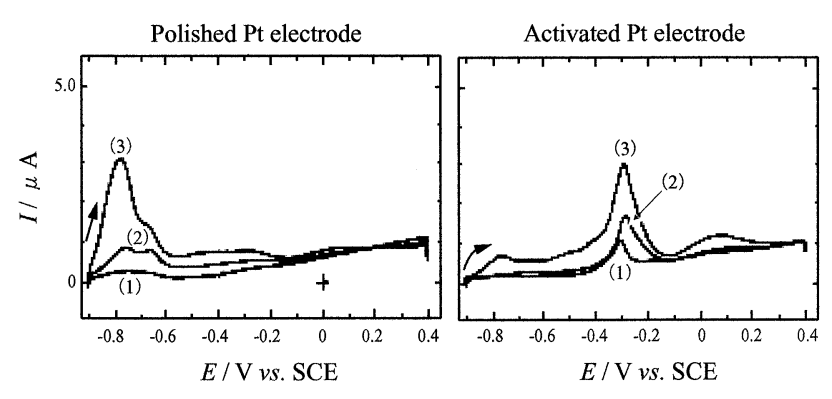

Fig. 9 Activation effect by laser pulse irradiation on the CVs of samples containing a small amount of soft drinks: (a) carbonated drink, (b) lactic acid drink. The CVs at the polished Pt and at the activated Pt electrode are indicated on the left side and on the right side, respectively. (1) $0.1 \mathrm{~mol} \mathrm{dm}{ }^{-3} \mathrm{NaOH}$, (2) $50 \mathrm{~cm}^{3}$ of $0.1 \mathrm{~mol}$ $\mathrm{dm}^{-3} \mathrm{NaOH}+0.200 \mathrm{~cm}^{3}$ soft drink, (3) $50 \mathrm{~cm}^{3}$ of $0.1 \mathrm{~mol} \mathrm{dm}^{-3} \mathrm{NaOH}$ $+0.200 \mathrm{~cm}^{3}$ soft drink $+0.3 \mathrm{mmol}$ glucose. The other conditions are as in Fig. 2.

can be seen in this figure, the oxidation waves II hardly appear at the polished electrode. In particular, a small addition of the lactic acid drink totally prevented the appearance of oxidation wave II (the curves (b)-(2) and (3) at the polished Pt electrode). In contrast to the polished electrode, the activated electrode gave oxidation wave II even for samples containing the lactic acid drink, indicating that the cleaning effect by laser pulse irradiation is very effective for voltammetric analyses of samples containing electrode-fouling substances.

The results from the voltammetric analyses are given in Table 1. The standard addition method was used for the determination. For a comparison, amperometric determination with the enzyme electrode ${ }^{16-18}$ and spectrophotometric determination were also carried out. ${ }^{20}$ The results by these methods are also summarized in Table 1 . The values from the amperometric and spectrophotometric determinations agree well, whereas the values from voltammetric determinations at the activated Pt electrode are two or three-times higher. This is because the activated Pt electrode is not selective to glucose, as previously described. Hence, the values from the voltammetric determinations probably indicate the total concentration of the monosaccharides contained in the samples. Table 2 lists the recovery of glucose added into the samples. The recoveries, which are almost $100 \%$, showed satisfactory results.

The above results obtained by cyclic voltammetry suggest that if we can activate a whole surface of the Pt electrode with a single laser pulse shot, LAV will be a more sensitive tool for the determination of any monosaccharide. Some improvements for achieving such an activation procedure are under investigation.
Table 1 Determination of glucose in soft drinks

\begin{tabular}{cccccc}
\hline Sample & $\begin{array}{c}\text { This work/ } \\
\text { mol dm }^{-3}\end{array}$ & $\begin{array}{c}\text { R.S.D., } \\
\% \\
(n=4)\end{array}$ & $\begin{array}{c}\text { Ampero- } \\
\text { metry/ } \\
\text { mol dm }^{-3}\end{array}$ & $\begin{array}{c}\text { R.S.D., } \\
\% \\
(n=4)\end{array}$ & $\begin{array}{c}\text { Spectro- } \\
\text { photometry/ } \\
\text { mol dm }^{-3}\end{array}$ \\
\hline (a) & 0.506 & 3.8 & 0.235 & 4.7 & 0.22 \\
(b) & 0.766 & 6.9 & 0.260 & 2.7 & 0.23 \\
\hline
\end{tabular}

(a) Carbonated drink, (b) lactic acid drink.

Table 2 Recovery of glucose added to soft drinks

\begin{tabular}{ccccc}
\hline Sample & $\begin{array}{c}\text { Added/ } \\
\mu \mathrm{mol}\end{array}$ & $\begin{array}{c}\text { Found/ } \\
\mu \mathrm{mol}\end{array}$ & $\begin{array}{c}\text { Recovery, } \\
\%\end{array}$ & $\begin{array}{c}\text { R.S.D., } \\
\%\end{array}$ \\
\hline Carbonated drink & 80 & 83 & 104 & 2.5 \\
Lactic acid drink & 80 & 82 & 103 & 4.2 \\
\hline
\end{tabular}

\section{Conclusions}

Using the Pt electrode activated by the laser pulse irradiation, the cyclic voltammograms of glucose in alkaline solution $(0.1$ mol $\mathrm{dm}^{-3} \mathrm{NaOH}$ ) were recorded. The oxidation wave due to hydrogen from glucose adsorbed on the electrode vanished and a sharp oxidation peak appeared at $-0.3 \mathrm{~V}$ in the sample containing glucose. Based on the oxidation mechanism of glucose reported in the literature, it is suggested that laser pulse irradiation changed the $\mathrm{Pt}$ electrode surface from a polycrystaline structure to a (111)-rich one. On the other hand, the activation effects, that is, the cleaning and surfacemodification effects by laser pulse irradiation, allowed the electrode to give a sharp oxidation wave at $-0.3 \mathrm{~V}$ even for real samples containing various electrode-fouling compounds. However, the activated Pt electrode was not selective to the electro-oxidation of glucose, but could respond to any monosaccharides in a similar way. Taking into account the lack of selectivity as well as a convenient procedure for the activation by laser pulse irradiation, the activated Pt electrode is expected to be a promissory tool as an amperometric detector for liquid chromatography, in particular, when used in laser ablation voltammetry (LAV).

\section{Acknowledgements}

We thank Prof. Shinsei Okuhara at Faculty of Medicine, Shinshu University, for his helpful cooperation in the spectrophotometric determination of glucose.

\section{References}

1. J. F. Rusling, Anal. Chem., 1984, 56, 575.

2. G. N. Kamau, W. S. Willis, and J. F. Rusling, Anal. Chem., 1985, 57, 545.

3. M. E. Rice, Z. Galus, and R. N. Adams, J. Electroanal. Chem., 1983, 143, 89.

4. W. J. Blaedel and R. Jenkins, Anal. Chem., 1974, 46, 1952.

5. F. G. Gonon, C. M. Fombarlet, M. J. Buda, and J. F. Pujol, Anal. Chem., 1981, 53, 1386.

6. R. C. Engstrom, Anal. Chem., 1982, 54, 2310.

7. K. J. Stutts, P. M. Kovach, W. G. Kuhr, and R. M. Wightman, Anal. Chem., 1983, 55, 1632. 
8. D. T. Fagan, I.-F. Hu, and T. Kuwana, Anal. Chem., 1985 , 57, 2759.

9. J. F. Evans and T. Kuwana, Anal. Chem., 1979, 51, 358.

10. C. W. Miller, D. H. Karweik, and T. Kuwana, Anal. Chem., 1981, 53, 2319.

11. M. Poon and R. L. McCreery, Anal. Chem., 1986, 58, 2745.

12. M. Poon and R. L. McCreery, Anal. Chem., 1988, 60, 1725.

13. T. Hinoue, I. Watanabe, and H. Watarai, Chem. Lett., 1996 329.

14. T. Hinoue, N. Kawamoto, and I. Watanabe, J. Electroanal. Chem., 1999, 466, 31.

15. M. Ohno and T. Hinoue, Chem. Lett., 2000, 752.

16. A. Okuda, F. Mizutani, and S. Yabuki, Hokkaidoritsu Kogyoshikennjyo Houkoku, 1991, 290, 173.

17. L. Gorton, H. I. Karan, P. D. Hale, T. Inagaki. Y. Okamoto, and T. A. Skotheim, Anal. Chim. Acta, 1990, 228, 23.

18. P. D. Hale, T. Inagaki, H. S. Lee, H. I. Karan, Y. Okamoto, and T. A. Skotheim, Anal. Chim. Acta, 1990, 228, 31.

19. W. E. Trevelyan and J. S. Harrison, Biochem. J., 1952, 50 , 298.

20. W. E. Neeley, Clin. Chem., 1972, 18, 509.

21. I. T. Bae, E. Yeager, X. Xing, and C. C. Liu, J. Electroanal. Chem., 1991, 309, 131.

22. K. D. Popović, N. M. Marković, A. V. Tripković, and R. R. Adžić, J. Electroanal. Chem., 1991, 313, 181.

23. H.-W. Lei, B. Wu, C.-S. Cha, and H. Kita, J. Electroanal. Chem., 1995, 382, 103.

24. Y. B. Vassilyev, O. A. Khazova, and N. N. Nikolaeva, J. Electroanal. Chem., 1985, 196, 127.

25. S. Ernst, J. Heitbaum, and C. H. Hamann, J. Electroanal. Chem., 1979, 100, 173.

26. Y. B. Vassilyev, O. A. Khazova, and N. N. Nikolaeva, $J$. Electroanal. Chem., 1985, 196, 105. 